\title{
THE LOCATION OF IMPURITIES IN ANTARCTIC ICE
}

\author{
by \\ E.W. Wolff and R. Mulvaney
}

(British Antarctic Survey, Natural Environment Research Council, High Cross, Madingley Road, Cambridge CB3 OET, England)

and

\section{K. Oates}

(Institute of Environmental and Biological Sciences, University of Lancaster, Bailrigg, Lancaster LA1 4YQ, England)

\begin{abstract}
Analysis of an ice sample with an estimated age of 125 years, from the Antarctic Peninsula, using a scanning electron microscope with a cold stage and an X-ray micro-analysis facility, shows that $\mathrm{H}_{2} \mathrm{SO}_{4}$ occurs mainly at triple junctions. Sea salts show no such localization. The different behaviour may be due to the freezing-point behaviour of each chemical substance, and to the effect this has both in the atmosphere and during recrystallization in the ice sheet. If this finding applies generally to other parts of the Antarctic ice sheet, it has major implications for many of the physical properties of Antarctic ice. In particular, it leads to a better understanding of the d.c. electrical conductivity of such ice.
\end{abstract}

\section{INTRODUCTION}

Over the last few years, it has been realized that, in order to understand fully the physical properties of Antarctic ice, it is necessary to characterize its chemistry. This involves knowledge not only of the concentration of impurities, but also of their distribution within the ice.

The location of some impurities in Antarctic ice seems to be fairly well understood. For instance, the gaseous components of the atmosphere are sealed off into bubbles at the firn-ice transition. In these bubbles are found the major gases $\left(\mathrm{N}_{2}, \mathrm{O}_{2}, A r\right)$, and also interesting trace gases, such as $\mathrm{CO}_{2}, \mathrm{CH}_{4}, \mathrm{~N}_{2} \mathrm{O}$ and fluorocarbons. At depth (for instance, below $1100 \mathrm{~m}$ in the Byrd Station core (Gow and Williamson 1975)), the bubbles disappear, possibly being squeezed into the ice lattice in the form of clathrate hydrates. Another impurity, hydrogen peroxide, is believed to be incorporated from the gas phase into the ice matrix by a co-condensation process (Sigg and Neftel 1988), without significant fractionation from water vapour. Hydrogen peroxide should therefore be quite uniformly distributed throughout snow crystals.

The major remaining impurities in ice are insoluble microparticles (of terrestrial origin), sea-salt aerosol (mainly $\mathrm{NaCl})$ and acids $\left(\mathrm{H}_{2} \mathrm{SO}_{4}, \mathrm{HNO}_{3}\right.$ and, in some cases, $\left.\mathrm{HCl}\right)$. The location and distribution of these materials in ice will depend on their mode of incorporation into snow-flakes or ice crystals, and on subsequent processes which occur during recrystallization in the ice sheet. This paper concentrates on the acid anion and sea-salt anion components.

\section{EXPERIMENTAL EVIDENCE FOR THE LOCATION OF IMPURITIES}

Wolff and Paren (1984) showed that both the magnitude and temperature dependence of the d.c. electrical conductivity of polar ice were well modelled if it was assumed that conduction took place through liquid layers of acid-water mixtures which were in equilibrium with ice at grain boundaries. These mixtures could remain liquid down to the eutectic points $\left(-73^{\circ} \mathrm{C}\right.$ for $\mathrm{H}_{2} \mathrm{SO}_{4},-43^{\circ} \mathrm{C}$ for $\mathrm{HNO}_{3}$ and $-75^{\circ} \mathrm{C}$ for $\mathrm{HCl}$ ), even with no supercooling. Thermodynamic arguments suggested that any liquid should occur preferentially at triple junctions, rather than at two-grain boundaries. Liquid triple junctions would form a network of veins through the ice structure. The model also applies if acids are found at sub-grain boundaries. For this mechanism to make polar ice as conductive as it is, most of the acid in the ice must be at boundaries rather than in the bulk.

This is highly indirect evidence for the location of impurities. To test the model directly, we examined ice using a scanning electron microscope (SEM), fitted with a cold stage (to $-160^{\circ} \mathrm{C}$ ) and an $\mathrm{X}$-ray micro-analysis facility. With this technique, secondary electron images can be obtained with a resolution of the order $10-100 \mathrm{~nm}$, and $\mathrm{X}$-ray spectra which show the location of chemical elements can be obtained at a resolution of the order of $1 \mu \mathrm{m}$. Nitrogen (N) cannot be measured by the instrument we used, but (of the major impurities) both sulphur (S) and chlorine $(\mathrm{Cl})$ should be detectable wherever they exceed a concentration of $\sim 5 \mathrm{mM}$.

An attempt was made to calibrate the system for ice by rapidly quenching individual $50 \mu \mathrm{l}$ droplets of $\mathrm{H}_{2} \mathrm{SO}_{4}$ solutions on to an Al block immersed in liquid nitrogen, in order to produce artificial standards. Unfortunately, the resulting standards were found to have formed crystals of $\sim 30 \mu \mathrm{m}$ dimension. The $\mathrm{S}$ was highly concentrated around all the grain boundaries in high concentration standards, and at triple junctions at lower concentration. The ice was highly inhomogeneous at all scales, which made it impossible to use for standards, so that we were forced to rely on earlier measurements made in gelatine standards (Wyness and others 1987). It might be possible to create more homogeneous standards by using an improved quenching procedure, but our experiment indicated the difficulty of preventing the acid partitioning to boundaries.

The Antarctic ice sample was cut from a core collected from Dolleman Island $\left(70^{\circ} 35.2^{\prime} \mathrm{S}, 60^{\circ} 55.5^{\prime} \mathrm{W}\right.$; $398 \mathrm{~m}$ a.s.1.; $10 \mathrm{~m}$ temperature $-16.75^{\mathrm{C}}$ ), situated at the edge of Larsen Ice Shelf in the Antarctic Peninsula. The results described here apply to a section from $65 \mathrm{~m}$ depth (just below pore close-off at this site) with an estimated age of 125 years. The bulk of impurity in the ice consisted of $\mathrm{H}_{2} \mathrm{SO}_{4}$ $(7.5 \mu \mathrm{M}), \mathrm{HNO}_{3}(0.7 \mu \mathrm{M})$ and sea salt $\left(9.0 \mu \mathrm{M} \mathrm{Cl}^{-}\right)$. Based on a sea-salt ${ }^{3} \mathrm{Cl} / \mathrm{Na}$ ratio of 1.165 , the measured $\mathrm{Na}^{+}$ $(7.9 \mu \mathrm{M})$ accounts for all of the $\mathrm{Cl}^{-}$and suggests there can be virtually no $\mathrm{HCl}$ in the sample. These values are typical of summer precipitation at this site (Mulvaney and Peel 1988), where the proximity of the Weddell Sea $(10 \mathrm{~km})$ provides an open-water source area during the summer for sea salt and for the precursors of $\mathrm{H}_{2} \mathrm{SO}_{4}$. 
The sample was prepared for the SEM by planing a small piece of ice (mounted on a $10 \mathrm{~mm}$ diameter SEM stub) with a sledge microtome in a cold-room at $-20^{\circ} \mathrm{C}$. The ice was transported in a container surrounded by dry ice, then cooled in liquid nitrogen before being mounted on the cold stage of the SEM. Further details of the preparation, and of the results obtained on the SEM, are described by Mulvaney and others (1988).

The electron-microscope image showed that the sample consisted of several crystals (average cross-sectional area on the cut surface of $1.8 \mathrm{~mm}^{2}$ ) and air bubbles. Grain boundaries were clearly visible, and they were easily distinguished from a crack that crossed the sample. No sub-structure was visible at a resolution of $20 \mathrm{~nm}$ or less. A typical triple junction is shown in Figure 1.

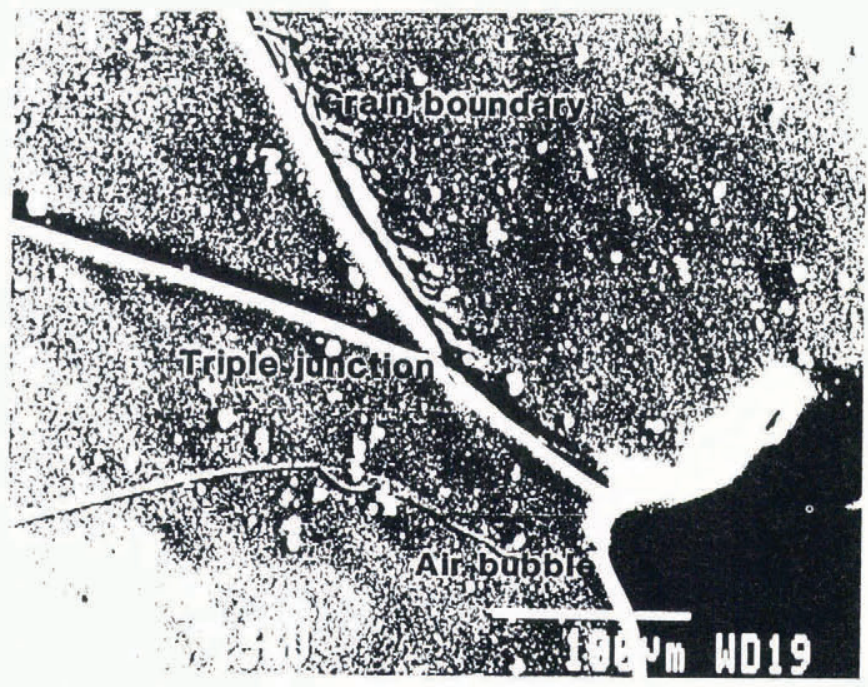

Fig. 1. A SEM photograph of a triple junction near an air bubble in ice from the Antarctic Peninsula. The white material is the residue from cutting the sample, and marks from the blade are also visible. A signal for sulphur is observed only in a small area (less than $\left.1 \mu \mathrm{m}^{2}\right)$ at the triple junction.

As described elsewhere (Mulvaney and others 1988), no $\mathrm{S}$ or $\mathrm{Cl}$ was detectable in areas of $1 \mu \mathrm{m}^{2}$ at the centre of grains or at two-grain boundaries. Large $\mathrm{S}$ peaks, but still no $\mathrm{Cl}$ peaks, were found at each of three triple junctions investigated. X-ray maps of these areas were consistent with the presence of $\mathrm{S}$ in areas of less than $1 \mu \mathrm{m}^{2}$. The size of the $S$ signal varied between triple junctions, but it is estimated that the concentration of $\mathrm{S}$ in the triple junctions will be approximately $2.5 \mathrm{M}$ (if the area is $1 \mu \mathrm{m}^{2}$, or higher if the area is smaller), with a large uncertainty. We use the model of ice grains as semi-regular truncated octahedra (Frank 1968, Nye and Frank 1973), with diameter between square faces of $d$, and triple junctions of cross-sectional area $A$ on each edge. The volume of a grain is $0.5 d^{3}$, and each of 36 edges (each shared between three grains) is $0.25 \sqrt{2} d$ long. This leads to a fractional volume of channels, $f=6 \sqrt{2} \mathrm{~A} / \mathrm{d}^{2}$. Our measured area of $1.8 \mathrm{~mm}^{2}$ would underestimate the size of crystals, because the surface cuts through the apex of some crystals. We therefore choose, as a reasonable estimate, $d=1.8 \mathrm{~mm}$. For $A=1 \mu \mathrm{m}^{2}$ this gives $f=2.62 \times 10^{-6}$. If the triple-junction liquid contains $2.5 \mathrm{M} \mathrm{H}_{2} \mathrm{SO}_{4}$, and taking into account the density of ice, this implies a melt-water concentration from the triple junctions alone of about $7 \mu \mathrm{M}$. This suggests that between 40 and $100 \%$ (best estimate $90 \%$ ) of the $\mathrm{H}_{2} \mathrm{SO}_{4}$ in the ice is at triple junctions. A similar calculation, based on the fact that no $\mathrm{Cl}$ peak was seen, suggests that less than $1 \%$ of the $\mathrm{NaCl}$ in the ice is at triple junctions.

The high concentration of $\mathrm{S}$ strongly suggests that the $\mathrm{S}$ was present as an $\mathrm{H}_{2} \mathrm{SO}_{4} / \mathrm{H}_{2} \mathrm{O}$ liquid mixture, in equilibrium with ice at the temperatures in the ice sheet. In our experiment, this liquid would have frozen in place at the eutectic temperature $\left(-73^{\circ} \mathrm{C}\right)$ and composition (4.9 M).
This experiment does not allow any decision about whether acids are also present as films at two-grain boundaries or on the surface of air bubbles. Such films would only be of nanometre thickness and would therefore be undetected in a $1 \mu \mathrm{m}^{2}$ footprint. However, it appears that most of the $\mathrm{H}_{2} \mathrm{SO}_{4}$ in this sample exists in a network of veins at triple junctions. Further work is needed to determine: (1) whether this finding applies also to $\mathrm{HNO}_{3}$ and $\mathrm{HCl}$, and (2) whether it applies to other locations in the Antarctic (and Greenland), and to deeper samples.

\section{THE ORIGIN OF THE LOCALIZATION}

It is necessary to explain why $\mathrm{H}_{2} \mathrm{SO}_{4}$ occurs at triple junctions, whereas sea-salt chloride does not (and therefore presumably exists within the grains or possibly at the two-grain boundaries). The localization must be due either to processes in the atmosphere or to processes which occur in the ice sheet during recrystallization.

\subsection{Atmospheric processes}

Aerosol can be incorporated into snow-flakes or ice crystals either in the cloud while the snow-flake is growing, below the cloud as the snow-flake falls, or on the ground by dry deposition. The last two processes will certainly leave material on the outside of snow-flakes, but Shaw (1980) estimates that in-cloud removal accounts for $90 \%$ of aerosol deposition on the Antarctic plateau. For the Antarctic Peninsula, Dick (unpublished) also found that most aerosol is removed in-cloud. Although the larger crustal component is probably removed mainly by nucleation, Dick (unpublished) believes that marine and sulphate aerosols are removed by riming - that is, by the uptake of supercooled cloud droplets which contain aerosol by ice crystals in the cloud.

$\mathrm{H}_{2} \mathrm{SO}_{4}$ exists as a hydrated liquid in the atmosphere (Shaw 1983) and, with its eutectic temperature of $-73^{\circ} \mathrm{C}$, is unlikely to freeze in most of the Antarctic atmosphere. It can act as a cloud-condensation nucleus, and is also probably present as a film on the exterior of clay-mineral particles. Because they are not solid, $\mathrm{H}_{2} \mathrm{SO}_{4}$ droplets cannot alone act as ice nuclei. Whether sulphuric acid is incorporated into snow crystals as a film on a solid nucleus or added by riming, we expect it to remain as a liquid on the outside of the growing crystal. If freezing is very fast, it might be trapped in the lattice, but our own experience with artificial samples suggests that such conditions are hard to obtain. $\mathrm{HNO}_{3}$ is believed to be captured directly from the gas phase. Once it has been incorporated into cloud droplets, we expect it to behave similarly to $\mathrm{H}_{2} \mathrm{SO}_{4}$, at least down to its eutectic temperature of $-43^{\circ} \mathrm{C}$.

$\mathrm{NaCl}$, on the other hand, may be considered insoluble below its eutectic temperature of $-21^{\circ} \mathrm{C}$. As a result, over most of Antarctica, $\mathrm{NaCl}$ crystals can act as ice nuclei, and riming should lead to further crystallization of $\mathrm{NaCl}$. In either case, solid aggregates of $\mathrm{NaCl}$ will result. However, in the Antarctic Peninsula in summer, clouds may be warmer than $-21^{\circ} \mathrm{C}$, so some $\mathrm{NaCl}$ may be present as a liquid film on the outside of crystals.

\subsection{Processes in the ice sheet}

Once the snow-flake has fallen, recrystallization and grain growth may alter the position of impurities. Alley and others $(1986 \mathrm{a}, \mathrm{b})$ believe that, in this process, microparticles will not be partitioned to boundaries, whereas soluble impurities will be. However, their model does not allow for the existence of any liquid at grain boundaries; although we have evidence only for liquid at triple junctions, care is required. Whether their model is correct or not, the presence of impurity in the lattice must cause strain (Alley and others 1986a), so that a lower energy will result if the impurity is retained at the boundary (especially if that is liquid). From this approach, irrespective of its starting point, a soluble impurity will end up at the grain boundary, although this thermodynamically preferred situation may not be reached rapidly if the impurity is aggregated.

At the temperature of most of the Antarctic ice sheet, $\mathrm{H}_{2} \mathrm{SO}_{4}$ can be considered soluble, but $\mathrm{NaCl}$ is not, and will 
probably not be partitioned to the boundary. For a warm site such as ours in the Antarctic Peninsula, $\mathrm{NaCl}$ may be present initially as a liquid, but should freeze out in the first winter after it falls, to form small volumes of pure $\mathrm{NaCl}$. Since the mean ice-sheet temperature at our site is $-17^{\circ} \mathrm{C}$, we expect $\mathrm{NaCl}$ to be partitioned subsequently to the boundaries. Our finding that $\mathrm{NaCl}$ has not reached the triple junctions in ice from just below the close-off depth at this site suggests that the thermodynamically preferred situation has not been reached.

In summary, processes in the atmosphere and ice sheet seem wholly consistent with the partitioning of sulphuric acid to grain boundaries to form a liquid film. Previous discussion (Wolff and Paren 1984) showed that the triple junctions would then be a more favoured location for the liquid than two-grain boundaries. In most of the Antarctic, where $\mathrm{NaCl}$ can be considered insoluble, we do not expect it to be partitioned to the boundaries. In the Antarctic Peninsula, the situation in respect of $\mathrm{NaCl}$ is less clear. Only further study of ice from various sites and depths can show whether the above discussion has identified correctly the factors involved.

\section{THE IMPLICATIONS FOR THE PROPERTIES OF ICE}

Many of the physical properties of ice must be affected by the presence of liquid (Paren and Walker 1971) at triple junctions. A discussion of some of them follows. It should be emphasized that currently we have evidence for the existence of triple-junction liquid only in ice from one site. The following sections are therefore of a speculative nature.

\subsection{Electrical properties}

If the finding that most of the acid in Antarctic ice is at triple junctions applies generally (and Antarctic Peninsula ice does not appear to have anomalous electrical properties), then the model of Wolff and Paren (1984) for d.c. conductivity should apply. This model relies on the existence of a continuous network of veins to provide conduction pathways. Some veins are cut by air bubbles in the upper parts of the ice sheet. Unless the bubbles also have a surface conducting film, they will reduce the derived conductivity. This should become less important with depth, as bubbles become separated from boundaries, and eventually disappear altogether at greater depth.

It is generally assumed that scratch electrical conductivity profiling (Hammer 1980) essentially measures the d.c. conductivity of ice. Legrand and others (1987) found that, in such a profiling experiment, ice which contains $\mathrm{HNO}_{3}$ or $\mathrm{HCl}$ is more conductive than ice which contains the same acid concentration in the form of $\mathrm{H}_{2} \mathrm{SO}_{4}$. This finding supports the idea that conduction takes place through liquid veins, since only one proton of $\mathrm{H}_{2} \mathrm{SO}_{4}$ will be dissociated at the high concentration in veins (Zanolini 1983, Wolff and Paren 1984).

A theory about acid veins surrounding less conductive ice crystals has not yet been discussed fully for the electrical properties of ice at high frequencies (including those relevant to radio echo-sounding), but is being developed (Moore and others 1988).

\subsection{Flow of ice}

Our initial expectation is that the presence of liquid at triple junctions may have a significant effect on the mechanism and magnitude of ice deformation. Previous authors (for example, Shoji and Langway (1984)), have assumed that ice with a high impurity content may be softer than other ice, but this idea has not been applied specifically to acid impurities in Antarctic ice. A re-appraisal of creep mechanisms (Goodman and others 1981, Lliboutry and Duval 1985), which takes into account the possible existence of liquid at triple junctions, seems appropriate.

\subsection{Other properties of polar ice}

Many other physical properties may also be affected by the presence of liquid. Here, we mention only two of them. The processes involved in grain growth have recently been discussed extensively (Alley and others 1986a, b).
However, their analysis did not allow for the presence of any liquid, and may require re-appraisal. We also note that the process of diffusion of impurities takes a surprising form in this case. Whereas the presence of liquid may have led us to expect fast diffusion of acid, this is clearly not the case, since seasonal variations in acid concentration are well preserved in the ice. The reason for this may be that there is no concentration gradient to drive diffusion. The concentration in the veins is determined solely by temperature (since the system must be on the freezing line of its phase diagram), so that, in isothermal ice, the veins all contain the same concentration of acid; only the size of the veins changes.

\subsection{Wisconsin ice}

In contrast to the Antarctic, Wisconsin-age ice from Greenland is not acidic (Hammer and others 1985), because the acids have been neutralized by alkaline dusts. If the neutralization occurs in the atmosphere, then the resulting salts may not occur at triple junctions. Any salts occurring at triple junctions are unlikely to form a liquid, since most of those likely to be present (e.g. Ca salts) have eutectic temperatures only a few degrees below zero. This would explain the observed low d.c. conductivity of Greenland Wisconsin ice.

If liquid at triple junctions does affect the flow of ice (see section 4.2), then its likely absence in Wisconsin-age ice may be an important factor in modelling the flow of the Greenland ice sheet.

\subsection{Temperate ice}

Temperate-ice studies have been carried out mainly in mid-latitudes, where anthropogenic emissions may dominate the acid budget. It is well known that there is a flush of impurities from the snow-pack in spring, and that this causes ecological stress. It has also been suggested (Davies and others 1982) that some impurities may be eluted preferentially to others. If similar processes to those discussed here occur at the higher temperatures over temperate ice caps, then study of the location of acids in temperate snow-packs may help in the understanding of this problem.

\subsection{Artificial doped ice}

There are reasons, unrelated to an understanding of natural polar ice, for studying artificial ice in the laboratory. However, where doped ice is used as an analogue for Antarctic ice, our results suggest that great caution is needed. It may be necessary to mimic not only the concentrations, but also the distribution of impurities in the ice if realistic results are to be obtained. Creating a particular distribution will be a difficult, if not impossible, task.

\section{CONCLUSIONS}

The most urgent requirement is that studies are carried out to see if acids occur at triple junctions in ice from areas outside the Antarctic Peninsula. If the findings apply also to deeper ice, to ice from central Antarctica and from Greenland, then a re-appraisal of some of the physical properties of ice will be required.

\section{ACKNOWLEDGEMENTS}

The authors thank Professor W.T.W. Potts, and many colleagues in the glaciology community, for their helpful comments.

\section{REFERENCES}

Alley, R.B., J.H. Perepezko, and C.R. Bentley, $1986 \mathrm{a}$ Grain growth in polar ice: I. Theory. J. Glaciol., 32(112), 415-424.

Alley, R.B., J.H. Perepezko, and C.R. Bentley. 1986b. Grain growth in polar ice: II. Application. J. Glaciol., 32(112), 425-433.

Davies, T.D., C.E. Vincent, and P. Brimblecombe. 1982. 
Preferential elution of strong acids from a Norwegian ice cap. Nature, 300(5883), 161-163.

Dick, A.L. Unpublished. Trace elements in Antarctic snow and air. (Ph.D. thesis, Council for National Academic Awards, 1987.)

Frank, F.C. 1968. Two-component flow model for convection in the Earth's upper mantle. Nature, 220, 350-352.

Goodman, D.J., H.J. Frost, and M.F. Ashby. 1981. The plasticity of polycrystalline ice. Philos. Mag., A43(3), 665-695.

Gow, A.J., and T. Williamson. 1975. Gas inclusions in the Antarctic ice sheet and their glaciological significance. J. Geophys. Res., 80(36), 5101-5108.

Hammer, C.U. 1980. Acidity of polar ice cores in relation to absolute dating, past volcanism, and radio-echoes. $J$. Glaciol., 25(93), 359-372.

Hammer, C.U., H.B. Clausen, W. Dansgaard, A. Neftel, P. Kristinsdottir, and E. Johnson. 1985. Continuous impurity analysis along the Dye 3 deep core. In Langway, C.C., jr, H. Oeschger, and W. Dansgaard, eds. Greenland ice core: geophysics, geochemistry, and the environment. Washington, DC, American Geophysical Union, 90-94. (Geophys. Monogr., 33.)

Legrand, M., J.-R. Petit, and Ye.S. Korotkevich. 1987. D.C. conductivity of Antarctic ice in relation to its chemistry. J. Phys. (Paris), 48, Colloq. C1, 605-611. (Supplèment au 3.)

Lliboutry, L., and P. Duval. 1985. Various isotropic and anisotropic ices found in glaciers and polar ice caps and their corresponding rheologies. Ann. Geophys., 3(2), 207-224.

Moore, J.C., R. Mulvaney, J.G. Paren, and E.W. Wolff 1988. The link between chemistry and the electrical properties of ice (abstract). Ann. Geophys. 1988. Special Issue, 136.
Mulvaney, R., and D.A. Peel. 1988. Anions and cations in ice cores from Dolleman Island and the Palmer Land plateau, Antarctic Peninsula. Ann. Glaciol., 10, 121-125.

Mulvaney, R., E.W. Wolff, and K. Oates. 1988. Sulphuric acid at grain boundaries in Antarctic ice. Nature, $331(6153), 247-249$.

Nye, J.F., and F.C. Frank. 1973. Hydrology of the intergranular veins in a temperate glacier. IASH Publ. 95 (Symposium at Cambridge $1969-$ Hydrology of glaciers), 157-161.

Paren, J.G., and J.C.F. Walker. 1971. Influence of limited solubility on the electrical and mechanical properties of ice. Nat., Phys. Sci., 230(12), 77-79.

Shaw, G.E. 1980. Optical, chemical and physical properties of aerosols over the Antarctic ice sheet. Atmos. Environ., 14(8), 911-921.

Shaw, G.E. 1983. X-ray spectrometry of polar aerosols. Atmos. Environ., 17, 329-339.

Shoji, H., and C.C. Langway, jr. 1984. Flow behavior of basal ice as related to modeling considerations. Ann. Glaciol., 5, 141-148.

Sigg, A., and A. Neftel. 1988. Seasonal variations in hydrogen peroxide in polar ice cores. Ann. Glaciol., 10, 157-162.

Wolff, E.W., and J.G. Paren. 1984. A two-phase model of electrical conduction in polar ice sheets. J. Geophys. Res., 89(B11), 9433-9438.

Wyness, L.E., J.A. Morris, K. Oates, W.G. Staff, and H. Huddart. 1987. Quantitative X-ray microanalysis of bulk hydrated specimens: a method using gelatine standards. J. Pathol., 153, 61-69.

Zanolini, F. 1983. Conductimétrie et chimie de la glace à D57 (Terre Adélie): application à la recherche $d u$ paléovolcanisme. Paris, Centre National de la Recherche Scientifique. (Bull. PIRPSEV, 76.) 